\title{
Velocidade de Processamento, Sintomas Depressivos e Memória de Trabalho: Comparação entre Idosos e Portadores de Esclerose Múltipla
}

\author{
Processing Speed, Depressive Symptoms and Working Memory: A Comparison \\ between Aging Individuals and Multiple Sclerosis Patients
}

\author{
Fernanda de Oliveira Ferreira ${ }^{*}, a$, Eduardo de Paula Lima ${ }^{b, c}$, Alina Gomide Vasconcelos ${ }^{b}$, \\ Marco Aurélio Lana-Peixoto ${ }^{b}, \&$ Vitor Geraldi Haase ${ }^{b}$ \\ ${ }^{a}$ Universidade Federal dos Vales do Jequitinhonha e Mucuri, Diamantina, Brasil \\ ${ }^{b}$ Universidade Federal de Minas Gerais, Belo Horizonte, Brasil \\ $\&{ }^{c}$ Corpo de Bombeiros Militar de Minas Gerais, Belo Horizonte, Brasil
}

\begin{abstract}
Resumo
A esclerose múltipla (EM) e o envelhecimento normal comprometem a substância branca hemisférica, causando déficits neuropsicológicos na função executiva, memória de trabalho (MT) e velocidade de processamento de informação (VPI). Foram investigadas as hipóteses: (a) a VPI pode constituir um fator determinante dos déficits de MT em pacientes com EM e idosos, e (b) sintomas depressivos auto-relatados podem agravar os déficits cognitivos de pacientes com EM. Participaram do estudo 31 pacientes com EM sem depressão, 36 portadores de EM deprimidos, 108 controles demograficamente comparáveis e 100 idosos da comunidade. Os grupos tiveram seus desempenhos comparados em uma escala de auto-relato para depressão e em uma bateria de testes para MT. Os resultados mostraram que o desempenho em MT depende da VPI, dos sintomas depressivos, da idade e da escolaridade dos indivíduos, variáveis que interagem de formas complexas.

Palavras-chave: Esclerose Múltipla; Envelhecimento; Memória de Trabalho; Velocidade de Processamento de Informação; Neuropsicologia.

Abstract

Damage to the hemispheric white matter is observed both in multiple sclerosis (MS) and normal aging, causing neuropsychological deficits in tasks of executive function, working memory (WM), and speed of information processing (SPEED). In this study two main hypotheses were investigated: (a) that SPEED may constitute a determining factor of WM impairment in MS patients and in aging individuals; (b) that self-reported depressive symptoms may aggravate cognitive deficits in MS patients. The study investigated 31 elderly MS patients without depression, 36 depressed ones, 108 demographically comparable controls and 100 community recruited senior participants. Performance of the groups was compared on a self-report measure of depression and on a WM test battery. Results showed that WM performance depends on SPEED, depressive symptoms, age, and schooling - variables which interact in complex ways. Keywords: Multiple Sclerosis; Aging; Working Memory; Speed of Information Processing; Neuropsychology.
\end{abstract}

As similaridades de manifestações neuropsicológicas relacionadas a diversos tipos de lesões da substância branca hemisférica cerebral são objeto de interesse crescente, tendo sido inclusive cunhado o termo "demência subcortical" ou "transtorno cognitivo da substância branca"

\footnotetext{
"Endereço de correspondência: Universidade Federal dos Vales do Jequitinhonha e Mucuri, Depertamento de Ciâncias Básicas. Rua da Glória, 187, Centro, CEP 39100-000, Diamantina, MG, Brasil. E-mail: ferreira.ufvjm@gmail.com
}

(Filley, 2005; Rao, 1986, 1996). Diversas condições, tais como diabete juvenil (Kail, Wolters, Yu, \& Hagen, 2000), encefalopatia por AIDS (Reger, Welsh, Razani, Martin, \& Boone, 2002) e esclerose múltipla (Demaree, DeLuca, Gaudino, \& Diamond, 1999; Thornton \& Raz, 1997) se caracterizam por um perfil de comprometimento neuropsicológico em que sobressaem sintomas psiquiátricos, déficits nas funções executivas, nas operações de resgate da memória episódica e na memória de trabalho (MT). Entretanto, a característica mais saliente é uma lentidão no processamento de informação, que pode se manifes- 
tar apenas em testes perceptivos e cognitivos (quando leve) ou até mesmo clinicamente, como bradipsiquismo (quando mais grave).

Déficits cognitivos decorrentes de alterações na substância branca hemisférica são observados também no contexto do envelhecimento, tanto normal quanto patológico (Campbell \& Coffey, 2001). As pesquisas sugerem certa continuidade neuropatológica entre alterações normalmente observáveis da substância branca no envelhecimento e situações patológicas, tais como EM e as demências vasculares, o transtorno cognitivo leve e, até mesmo, a doença de Alzheimer (Frisoni \& Filippi, 2005). As lesões vasculares multifocais da substância branca podem, inclusive, predispor o indivíduo a quadros psiquiátricos, tais como, a depressão (Campbell \& Coffey, 2001). A revisão da literatura sugere, portanto, que comprometimentos da substância branca, lentidão do processamento de informação e sintomas depressivos podem interagir de forma complexa na determinação da funcionalidade cognitiva e emocional tanto de pacientes neurológicos quanto de idosos normais.

As semelhanças de manifestações neuropsicológicas entre as doenças primordialmente da substância branca e condições relacionadas ao envelhecimento normal, principalmente o comprometimento da velocidade de processamento, despertaram o interesse por realizar um estudo comparativo entre indivíduos com esclerose múltipla (EM) e pessoas idosas recrutadas na comunidade.

A esclerose múltipla (EM) é uma doença crônica e autoimune, caracterizada pela desmielinização, inflamação e neurodegeneração do sistema nervoso central. A EM é uma patologia subcortical, atingindo a substância branca do sistema nervoso central, mas também é possível que afete a substância cinzenta (Alvarenga \& Quirico-Santos, 1997; Rowland, 2002). Diversas pesquisas estão sendo realizadas a fim de esclarecer os mecanismos neuropatológicos complexos envolvidos na esclerose múltipla (Benedict, Carone, \& Bakshi, 2004; Hart et al., 2004; Vodjani, Vodjani, \& Cooper, 2003). A destruição da mielina, o dano axonal e a distribuição das lesões em placas, disseminadas preferencialmente pela substância branca, constituem os principais achados anatomopatológicos da EM (Alvarenga \& Quirico-Santos, 1997). Com o passar do tempo, dependendo da forma e curso da esclerose múltipla, pode ocorrer a atrofia cerebral como conseqüência da degeneração axonal (Rao et al., 1985). Existem quatro formas diferentes de evolução da doença, sugeridas por Lublin e colaboradores em 1996 (Lana-Peixoto et al., 2002). A forma recorrente-remitente ou surto-remissão evolui em surtos bem individualizados, que podem ou não deixar seqüelas, não havendo progressão dos déficits entre os surtos. Um surto é definido como um episódio subjetivo ou objetivo de distúrbio neurológico, com duração mínima de 24 horas. Pode-se considerar surtos separados quando há um intervalo mínimo de 30 dias entre os respectivos desen- cadeamentos. $\mathrm{Na}$ esclerose múltipla secundariamente progressiva a fase inicial caracteriza-se por surtos e remissões, no entanto, a doença evolui para a progressão dos déficits sem surtos ou com surtos subjacentes - forma secundariamente progressiva com surtos - havendo progressão da doença entre os surtos. A esclerose múltipla primariamente progressiva caracteriza-se desde o início como uma doença progressiva, sem a presença de surtos, evoluindo com eventuais estabilizações e raros períodos de leve melhora. Já a forma progressiva-recorrente também é caracterizada, desde o início, como progressiva, porém intercalada com surtos objetivos, com ou sem recuperação total, havendo progressão da doença entre os surtos.

A heterogeneidade de manifestações clínicas na EM dificulta enormemente o diagnóstico neuropsicológico. Pacientes com formas predominantemente medulares da doença podem apresentar déficits cognitivos discretos (Pelosi, Geesken, Holly, Hayward, \& Blumhardt, 1997), e um mesmo paciente pode apresentar lesões em diferentes estágios evolutivos: inflamatórias agudas, cicatriciais, degenerativas (Stadelmann \& Brück, 2008). A complexidade da expressão sintomática é potencializada pela existência de mecanismos de plasticidade sináptica. O esforço para realizar um determinado comportamento ativa áreas corticais adicionais, estando potencialmente relacionado ao sintoma de fadiga (DeLuca, Genova, Hillary, \& Wyllie, 2008). O estabelecimento dos déficits cognitivos representa o esgotamento dos mecanismos de neuroplasticidade.

Os sintomas neuropsicológicos e psiquiátricos da EM estão relacionados à diminuição da velocidade de condução axonal causada pelos processos inflamatórios e degenerativos. Segundo Calabrese (2006), o comprometimento da substância branca causa múltiplas desconexões entre áreas corticais e subcorticais. A manifestação sintomática depende tanto da localização quanto do acúmulo progressivo de lesões, tornando-se óbvia apenas quando um determinado limiar lesional é ultrapassado. Estudos longitudinais mostram que a probabilidade de déficits cognitivos aumenta com a evolução da doença (Amato, Zipoli, \& Portacio, 2006). Em alguns pacientes, os prejuízos cognitivos já podem ser detectados nas fases iniciais da patologia (Achiron \& Barak, 2003), por outro lado, outros pacientes permanecem relativamente indenes mesmo após 20 anos de evolução da doença. As desconexões múltiplas causam fadiga e redução da velocidade de processamento de informação (Diamond, Johnson, Kaufman, \& Graves, 2008). A redução da eficiência no processamento de informação prejudica as operações atencionais e de controle executivo sobre diversas formas de memória, pensamento e tomada de decisão (Arnett et al., 1997). O comprometimento da memória e funções executivas é explicado pela localização subcortical frontal das lesões, desconectando o córtex pré-frontal de outras estruturas corticais e subcorticais (Foong et al., 1997). 
Ferreira, F. O., Lima, E. P., Vasconcelos, A. G., Lana-Peixoto, M. A. \& Haase, V. G. (2011). Velocidade de Processamento, Sintomas Depressivos e Memória de Trabalho: Comparação entre Idosos e Portadores de Esclerose Múltipla.

A depressão maior é o quadro psiquiátrico na EM que maior atenção tem despertado devido a sua prevalência. A freqüência de depressão maior é da ordem de até $30 \%$ em estudos transversais e de $50 \%$ ao longo da vida entre portadores de EM (Goldman Consensus Group, 2005). Neuroanatomicamente, a depressão maior na EM foi atribuída a uma desconexão entre áreas frontais e límbicas, sendo associada a lesões do fascículo arqueado esquerdo (Pujol, Bello, Deus, Martí-Vilalta, \& Capdevila, 1997). Mas os sintomas de depressão também refletem ou são agravados pelas incertezas associadas à imprevisibilidade do curso clinico da doença (Zorzon et al., 2001). Uma das hipóteses a ser considerada é que, retroagindo sobre os déficits neurológicos, os sintomas depressivos na EM constituem um fator agravante com potencial para comprometer o funcionamento cognitivo, laboral e a qualidade de vida dos doentes. Em muitos pacientes com EM, os efeitos das lesões típicas da doença podem não se revestir de magnitude suficiente para ultrapassar o limiar sintomático clinico. No entanto, as alterações neuropatológicas inflamatórias e degenerativas observadas na EM podem se sobrepor aos efeitos do processo de envelhecimento ou de sintomas depressivos, fazendo com que os déficits se expressem em alguns pacientes (Feinstein, 2006).

A heterogeneidade sintomática na EM é demonstrada também quanto ao tipo de sintomas neuropsicológicos e neuropsiquiátricos. Alguns poucos pacientes não apresentam quaisquer comprometimentos cognitivos ou psiquiátricos (Sayao, Devonshire, \& Tremlett, 2007), enquanto outros apresentam sintomas psiquiátricos ou cognitivos isolados, e um terceiro grupo de pacientes apresenta tanto sintomas psiquiátricos quanto déficits cognitivos (Lima, Haase, \& Lana-Peixoto, 2008). Em alguns pacientes, a presença de sintomas depressivos contribui para o agravamento dos déficits cognitivos (Arnett et al., 1999; Landro, Celius, \& Stetvold, 2004).

Landro et al. (2004) observaram que a presença de sintomas depressivos avaliados pelo Inventário Beck de Depressão ([IBD], Cunha, 2000) compromete o desempenho em testes de VPI e de memória de trabalho (Paced Auditory Serial Addition Test - PASAT, Single Digit Modalities Test-SDMT), porém, não houve prejuízo na realização de um teste de função executiva (Wisconsin Card Sorting Test - WCST). Arnett et al. (1999) examinaram a influência de sintomas depressivos auto-avaliados sobre o desempenho em um teste de MT, a tarefa de alcance de leitura (Reading Span Task - RST). Na RST, o participante precisa armazenar na memória de curto-prazo uma série de palavras apresentadas por escrito, ao mesmo tempo em que responde a perguntas verificando a compreensão de uma série de perguntas também apresentadas por escrito. $\mathrm{O}$ tamanho da série de perguntas $\mathrm{e}$ palavras que o examinando consegue responder e armazenar simultaneamente corresponde ao alcance de leitura. Os resultados de Arnett et al. (1999) mostraram que a presença de sintomas depressivos não interferiu no desempenho de um teste de alcance de apreensão de palavras (capacidade de armazenamento), prejudicando, entretanto, o desempenho na tarefa de alcance de leitura (componente executivo ou operacional da memória de curto-prazo).

Salthouse e Babcock (1991) desenvolveram um modelo de MT extremamente relevante para o contexto do envelhecimento e da EM. No modelo, o componente executivo da MT é operacionalizado por meio de uma tarefa de apreensão na escuta (listening span task - LST), a qual é equivalente à RST, diferenciando-se na forma oral de apresentação dos estímulos. Através de uma série de análises de regressão e em dois estudos independentes, Salthouse e Babcock (1991) demonstraram que o prejuízo em tarefas de MT associado ao envelhecimento podia ser explicado pela lentidão no processamento de informação. Em uma revisão posterior, Salthouse (1996) demonstrou que a lentidão do processamento de informação explica mais do que $90 \%$ da variância no envelhecimento cognitivo normal. Um conjunto de tarefas para avaliação do modelo foi validado para uso no Brasil ([BAMT-UFMG], Wood, Rothe-Neves, Carvalho, \& Haase, 2001). O modelo propõe que o componente executivo da MT (avaliado pela tarefa de alcance de apreensão na escuta) corresponda à capacidade de coordenar simultaneamente e de forma rápida e eficiente tarefas de armazenamento (alcance de apreensão de palavras ou dígitos) e velocidade de resolução de problemas verbais ou aritméticos simples.

Pode-se considerar que, no modelo processual de MT proposto por Salthouse e Babcock (1991), a capacidade de coordenação corresponde ao executivo central e a capacidade de armazenamento aos sistemas escravos do modelo de MT proposto por Baddeley e Hitch (Baddeley, 1992, 2003). O modelo pressupõe adicionalmente que, tanto a coordenação de operações quanto a capacidade de armazenamento dependem criticamente da VPI, a qual está comprometida na EM (Demaree et al., 1999). Por exemplo, em um momento psicológico com duração de três segundos um sistema, que processa informação a 40 bits/s apresenta o dobro da capacidade de armazenamento de um sistema que processa informação a 20 bits/s. No estudo de Demaree et al. (1999), foram utilizadas duas versões de uma mesma tarefa de vigilância, observandose que a acurácia de portadores de EM e de controles foi idêntica quando os pacientes podiam realizar o teste em um ritmo mais lento. A velocidade de processamento é um componente tão crucial do déficit cognitivo na EM, que o Paced Auditory Addition Test (PASAT), uma tarefa que impõe enorme pressão de tempo na sua resolução, acabou se firmando como o indicador mais acurado, uma espécie de padrão-ouro, das dificuldades cognitivas de portadores de EM (Cutter et al., 1999).

O presente estudo teve como objetivo, portanto, investigar a hipótese de que o desempenho de portadores de 
EM e idosos normais em testes de MT depende da velocidade de processamento de informação, a qual se encontra comprometida em ambos os grupos. Como a heterogeneidade clínica e patológica observada na EM faz com que nem todos os pacientes ultrapassem o limiar de expressão sintomática para déficits em tarefas de MT, foi investigada, adicionalmente, a hipótese de que os déficits de MT em pacientes com EM serão mais evidentes naqueles indivíduos que apresentarem sintomas autorelatados de depressão. O pressuposto foi que pequenos comprometimentos da VPI observados em fases relativamente iniciais da evolução da EM poderiam não ser suficientes para prejudicar o desempenho em tarefas de MT. Por outro lado, quando os déficits associados à EM são compostos por sintomas de depressão, as dificuldades se tornam evidentes.

Além disso, o presente trabalho objetivou verificar a acurácia da Bateria de Avaliação da Memória de Trabalho (BAMT- UFMG) para discriminar os seguintes grupos: pacientes com esclerose múltipla com e sem sintomas depressivos, controles jovens pareados quanto a idade, sexo e escolaridade, e idosos saudáveis. Dessa forma, foi possível avaliar comparativamente a magnitude dos efeitos de um processo patológico como a EM, com ou sem depressão, e do envelhecimento cerebral normal sobre o desempenho em tarefas de MT e de VPI.

\section{Método}

\section{Procedimentos}

Os procedimentos e Termo de Consentimento Livre e Esclarecido deste trabalho foram aprovados pelo Comitê de Ética em Pesquisa da Universidade Federal de Minas Gerais (COEP - UFMG). Inicialmente o participante realizava a leitura da carta-convite esclarecendo os objetivos e a natureza dos procedimentos e em seguida, concordando em participar do estudo, assinava o termo de consentimento livre e esclarecido. Os participantes foram avaliados individualmente em uma sala bem iluminada e silenciosa. No grupo clínico, as avaliações foram realizadas em um Centro de Referência em Esclerose Múltipla de um Hospital Universitário, ambulatório já freqüentado pelos pacientes, enquanto no grupo controle as avaliações foram executadas no domicílio do participante. Os participantes do grupo controle foram recrutados aleatoriamente na comunidade controlando as variáveis idade e escolaridade.

Foram avaliados o funcionamento cognitivo (habilidades visuoconstrutivas, memória de curto prazo, memória episódica, MT, aprendizagem, interferência, fluência de desenhos, memória pictorial, memória verbal, linguagem, atenção, VPI), além do funcionamento psicossocial (depressão e percepção da própria saúde mental). Os resultados da avaliação neuropsicológica são descritos parcialmente em outros estudos (Lima et al., 2008).
Com a conclusão da avaliação, os pacientes e familiares recebiam um relatório na entrevista de devolução dos resultados e sugestões de possíveis intervenções a fim de aprimorar a qualidade de vida do paciente. Quando necessário, foram realizados encaminhamentos para outros profissionais.

\section{Participantes}

Participaram deste estudo 275 indivíduos, sendo 67 pacientes com EM, 108 controles jovens, pareados quanto à idade, sexo e escolaridade aos portadores de EM, e 100 idosos recrutados na comunidade. Todos participaram voluntariamente no estudo, após o esclarecimento dos objetivos e obtenção do consentimento livre e esclarecido. Foram encontradas diferenças significativas com relação à idade e escolaridade na comparação dos quatro grupos utilizando ANOVA, uma vez que o grupo de idosos apresenta média de escolaridade mais baixa e idade média mais elevada, o que ressalta as diferenças entre os grupos.

Os participantes do grupo EM apresentaram uma média de duração da doença de $9,58(D P=7,64)$ anos, indicando que, de modo geral, os participantes estavam de um estágio inicial a intermediário de evolução da doença, em que se iniciam de forma mais significativa os comprometimentos motores e fisiológicos. Com relação à forma clínica, $64,5 \%$ dos pacientes com EM apresentavam a forma recorrente-remitente da doença, 13,6\% dos pacientes apresentavam a forma primariamente progressiva e $23,9 \%$, a forma secundariamente progressiva da EM. Nenhum paciente foi avaliado em período inferior a dois meses após o último surto.

Os pacientes com esclerose múltipla foram divididos em dois grupos (deprimidos e não deprimidos) de acordo com o resultado obtido no Inventário Beck de Depressão (IBD), considerando deprimidos os pacientes que obtiveram escore superior a 15 pontos no IBD, uma vez que esse foi o ponto de corte que apresentou maior acurácia para discriminação entre controles saudáveis e pacientes com esclerose múltipla em análises desenvolvidas com os dados (dados não publicados). As discussões apresentadas no artigo de Haase et al. (2004) ressaltam a relevância de se ter critérios cautelosos para identificação de sintomas depressivos na esclerose múltipla, uma vez que muitos dos sintomas característicos da doença assemelham-se a quadros depressivos. Dessa forma, optou-se por um critério mais rígido no estabelecimento do ponto de corte. A Tabela 1 descreve as características demográficas da amostra. É importante ressaltar que foram excluídos do estudo sete participantes do grupo controle jovens e um participante do grupo de idosos que apresentaram escores acima de 15 pontos no IBD. Dessa forma, os grupos de controles jovens e de idosos não apresentaram participantes com sintomas depressivos. 
Ferreira, F. O., Lima, E. P., Vasconcelos, A. G., Lana-Peixoto, M. A. \& Haase, V. G. (2011). Velocidade de Processamento, Sintomas Depressivos e Memória de Trabalho: Comparação entre Idosos e Portadores de Esclerose Múltipla.

Tabela 1

Dados Demográficos dos Participantes do Estudo

\begin{tabular}{|c|c|c|c|c|c|c|c|c|c|c|c|}
\hline & \multicolumn{2}{|c|}{$\begin{array}{l}\text { Controles } \\
\text { Jovens }\end{array}$} & \multicolumn{2}{|c|}{ Idosos } & \multicolumn{2}{|c|}{$\begin{array}{l}\text { Esclerose } \\
\text { Múltipla } \\
\text { (não deprimidos) }\end{array}$} & \multicolumn{2}{|c|}{$\begin{array}{l}\text { Esclerose } \\
\text { Múltipla } \\
\text { (deprimidos) }\end{array}$} & $F$ & $\begin{array}{l}\text { Graus de } \\
\text { Liberdade }\end{array}$ & $p$ \\
\hline \multirow{3}{*}{$\begin{array}{l}\text { Idade (anos) } \\
\text { Escolaridade (anos) }\end{array}$} & Média & DP & Média & DP & Média & DP & Média & DP & \multicolumn{3}{|c|}{ Entre-grupos } \\
\hline & 39,62 & 13,4 & 70,99 & 6,7 & 41,45 & 9,3 & 42,29 & 8,98 & 183,8 & 3 & 0,000 \\
\hline & 10,3 & 4,14 & 7,22 & 4,5 & 12,10 & 4,1 & 8,59 & 4,9 & 14,0 & 3 & 0,000 \\
\hline Sexo (\% feminino) & \multicolumn{2}{|c|}{$\begin{array}{c}\text { Frequência } \\
73,5 \%\end{array}$} & \multicolumn{2}{|c|}{$\begin{array}{l}\text { Frequência } \\
\quad 75 \%\end{array}$} & \multicolumn{2}{|c|}{$\begin{array}{c}\text { Frequência } \\
67,7 \%\end{array}$} & \multicolumn{2}{|c|}{$\begin{array}{l}\text { Frequência } \\
77,1 \%\end{array}$} & $\begin{array}{c}X^{2} \\
0,870\end{array}$ & 3 & 0,832 \\
\hline
\end{tabular}

Instrumentos

Instrumentos de Avaliação Neurológica

Expanded Disability Status Scale (EDSS). A EDSS

(Kurtzke, 1983) é uma escala ordinal amplamente utilizada na avaliação de portadores de esclerose múltipla e se baseia no exame neurológico de oito sistemas funcionais, a saber: (a) funções piramidais; (b) funções cerebelares; (c) funções do tronco cerebral; (d) funções vesicais e intestinais; (e) funções sensoriais; (f) funções visuais; (g) funções mentais; (h) outras funções ligadas a achados neurológicos compatíveis a esclerose múltipla (Kurtzke, 1983). A pontuação na EDSS varia de 0 a 10, em que 0 indica exame neurológico normal e 10 indica morte devido à esclerose múltipla.

Índice Ambulatorial (IA). O índice ambulatorial foi desenvolvido por Hauser et al. (1983) como uma forma simples de obter uma estimativa global da incapacidade física dos portadores de esclerose múltipla por meio de informações sobre a capacidade de deambulação do paciente. $\mathrm{O}$ examinador solicita ao paciente que caminhe oito metros de forma rápida, porém segura. $\mathrm{O}$ tempo gasto para execução da tarefa é cronometrado. A partir do desempenho do paciente é preenchida uma escala ordinal que varia de 0 (paciente assintomático) a 10 (paciente acamado).

\section{Instrumento de Avaliação Cognitiva}

Bateria de Avaliação da Memória de Trabalho (BAMT

- UFMG). A partir do modelo de memória de trabalho defendido por Salthouse e Babcock (1991), foi construída uma bateria de avaliação adaptada para a população brasileira, a Bateria da Avaliação da Memória de Trabalho ([BAMT-UFMG], Wood et al., 2001). A BAMT-UFMG é composta de tarefas de lápis e papel estruturalmente semelhantes, em duas modalidades: uma verbal e uma numérico-verbal, representando cada componente funcional da MT. As habilidades matemáticas ou de português exigidas pela BAMT-UFMG são mínimas, possibilitando utilizar a bateria mesmo com indivíduos com menos de quatro anos de escolarização. Cada modalidade possui três testes: (a) velocidade de processamento; (b) armazenamento; (c) coordenação de operações.
Nos testes de velocidade de processamento o participante deve resolver o maior número de problemas simples. Os problemas são apresentados em uma folha, seguidos de três opções de resposta, sendo computado o número de acertos emitidos em 20 segundos. Na modalidade numérica são apresentadas 27 operações aritméticas (Figura 1) e na modalidade verbal são apresentadas 25 sentenças com perguntas simples ao final, avaliando a compreensão da frase apresentada (Figura 2).

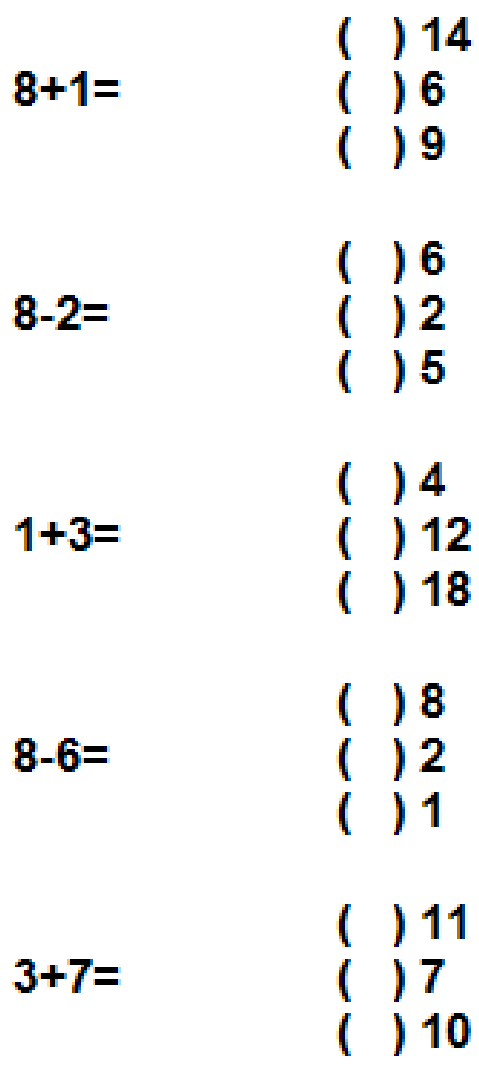

Figura 1. Exemplo dos itens de velocidade de processamento na modalidade numérica da BAMT-UFMG 
Os meninos brincaram muito de peteca e de bola. Quem?
( ) A janela
( ) Paulo
( ) Os meninos

Os vaqueiros sabem que o patrão gosta de gado. Quem gosta de gado?

( ) Os homens

( ) $O$ patrão

( ) A natureza

\section{A qualidade de vida se revelou boa naquela ilha.} $O$ quê?

( ) A qualidade de vida

( ) As curvas

( ) As florestas

\section{Sempre me surpreendo com tanta terra.}

Quem?

( ) Os peões

( ) Eu

( ) O dono da terra

\section{Os meninos queriam ganhar o jogo. Quem? \\ ( ) Os meninos \\ ( ) 0 treinador \\ ( ) O padre}

Figura 2. Exemplo dos itens de velocidade de processamento na modalidade verbal da BAMT-UFMG

Os testes de armazenamento consistem de tarefas simples medindo o alcance de apreensão de itens, dígitos na modalidade numérica, e palavras, na modalidade verbal. A tarefa inclui nove níveis de dificuldade, com três listas de itens em cada uma delas. Em cada nível é necessário que o respondente registre corretamente pelo menos duas listas para avançar para o próximo nível. $\mathrm{O}$ escore final corresponde ao número de itens que o indivíduo conseguiu reproduzir corretamente e varia entre 0 e 11. Na modalidade numérica a tarefa é iniciada com uma seqüência de três dígitos apresentados verbalmente ao respondente. Após a apresentação dos dígitos o respondente deve registrar a lista por escrito, na mesma ordem apresentada (Figura 3). Na modalidade verbal, o mesmo procedimento é realizado com listas de palavras (Figura 4).
Lista de Dígitos

Lista 1: $3,4,8$

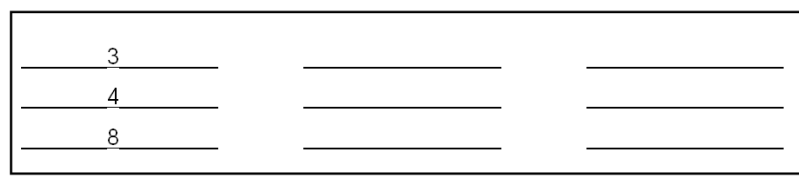

Lista 1: $9,2,5,6$

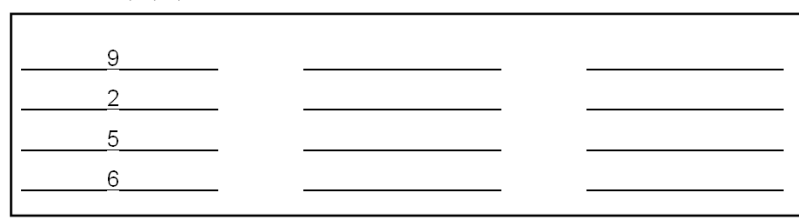

Figura 3. Exemplo dos itens de armazenamento na modalidade numérica da BAMT-UFMG

Lista de Palavras

Lista 1: foto, jiló, cola

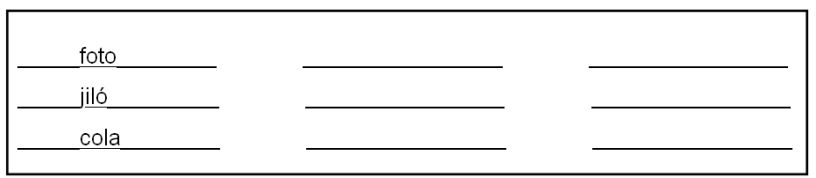

Lista 1: bote, jaca, maré, rede

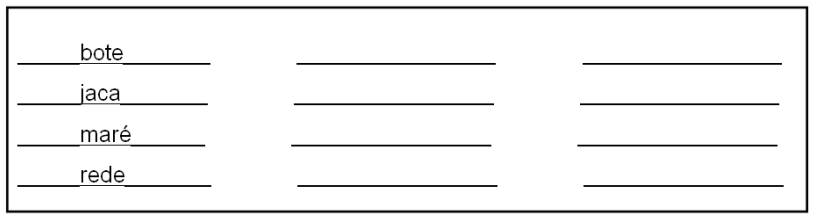

Figura 4. Exemplo dos itens de armazenamento na modalidade verbal da BAMT-UFMG

Os testes de coordenação envolvem a execução simultânea de duas tarefas: armazenamento de itens e resolução de problemas simples. A tarefa inclui sete níveis de dificuldade, com três listas de problemas apresentados em cada um deles. Em cada nível é necessário que o respondente resolva os problemas e memorize os itens indicados corretamente em pelo menos duas listas para avançar para o próximo nível. O escore final corresponde ao número de problemas e itens armazenados de forma simultânea que o indivíduo realizar corretamente e varia entre 0 e 7. Na modalidade numérica, o participante deve responder a uma série de problemas aritméticos simples, de adição e subtração, que são lidos pelo experimentador e, simultaneamente, memorizar o último dígito do problema lido pelo aplicador (Figura 5). Na modalidade verbal o experimentador lê frases, com grau de dificuldade sintática e semântica controlado, e o participante deve responder a questões sobre a compreensão das mesmas, ao mesmo tempo em que memoriza a última palavra da frase lida pelo experimentador (Figura 6). 


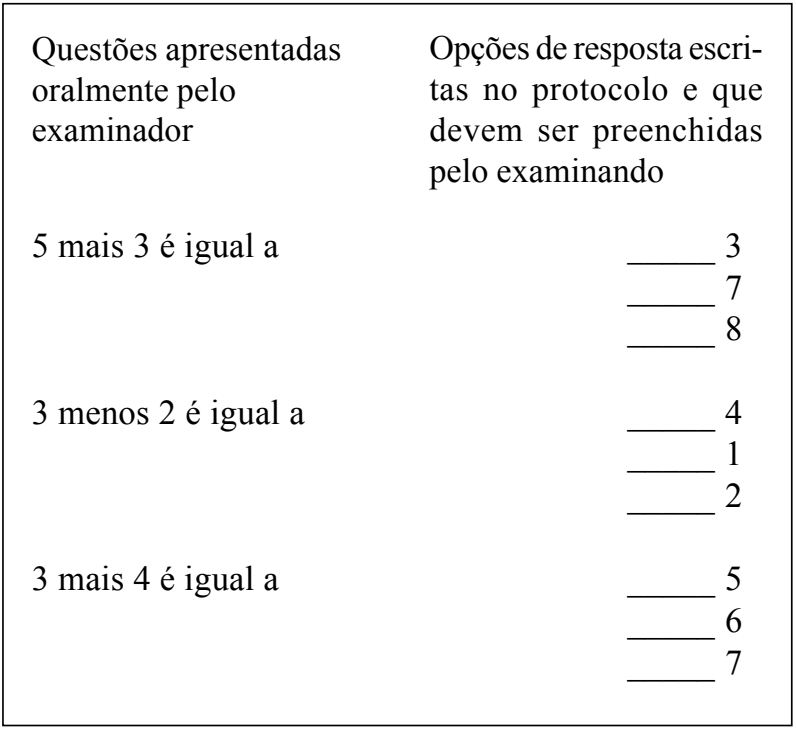

Figura 5. Exemplo dos itens de coordenação na modalidade aritmética da BAMT-UFMG

Nota. Nessa tarefa, o participante deve responder a questão e, ao mesmo tempo, memorizar o último número do cálculo dito pelo experimentador.

\begin{tabular}{|c|c|}
\hline $\begin{array}{l}\text { Questões apresentadas } \\
\text { oralmente pelo } \\
\text { examinador }\end{array}$ & $\begin{array}{l}\text { Opções de resposta escri- } \\
\text { tas no protocolo e que } \\
\text { devem ser preenchidas } \\
\text { pelo examinando }\end{array}$ \\
\hline $\begin{array}{l}\text { Suas amigas acham que } \\
\text { se confundiram com a }\end{array}$ & $\begin{array}{c}\text { roupa. Quem? } \\
\text { Suas amigas } \\
\text { Maria }\end{array}$ \\
\hline $\begin{array}{l}\text { Sua tia } \\
\text { Aquela senhora recebeu } \\
\text { um bilhete e procurou o } \\
\text { moço. }\end{array}$ & $\begin{array}{r}\text { Recebeu o que? } \\
\text { Um bilhete } \\
\text { Um cheque }\end{array}$ \\
\hline $\begin{array}{l}\text { A roupa } \\
\text { Eu pedi uma salada e } \\
\text { recebi uma sopa. }\end{array}$ & $\begin{array}{l}\text { Quem? } \\
\begin{array}{l}\text { O médico } \\
\text { Mamãe } \\
\text { Eu }\end{array}\end{array}$ \\
\hline
\end{tabular}

Figura 6. Exemplo dos itens de coordenação na modalidade verbal da BAMT-UFMG

Nota. Nessa tarefa, o participante deve responder a questão e, ao mesmo tempo, memorizar a última palavra dita pelo experimentador, ao realizar a pergunta.

\section{Instrumentos de Avaliação Psicossocial}

Inventário Beck para Depressão (IBD). O IBD avalia a presença de sintomas depressivos. Esse instrumento foi selecionado uma vez que este vem sendo utilizado com bons resultados em pesquisas com populações clínicas (Tanajura, Santos-Jesus, Tavares-Neto, \& Oliveira, 2002; Godoy \& Godoy, 2002), além de ter sido validado para a população brasileira (Cunha, 2000; Gorenstein \& Andrade, 1998) e já ter sido utilizado no Brasil em pacientes com esclerose múltipla (Haase et al., 2004; Mendes, Barão Cruz, Tilbery, Balsimelli, \& Moreira, 2003), o que possibilita eventuais comparações dos nossos resultados. O IBD também foi utilizado no trabalho de Haase et al. (2004), que teve o objetivo de avaliar o funcionamento psicossocial de pacientes com esclerose múltipla. Os resultados da avaliação de sintomas depressivos em pacientes com EM, utilizando o IBD demonstraram que $50 \%$ dos pacientes apresentaram presença de sintomas depressivos de magnitude moderada ou severa, enquanto no grupo controle esta freqüência foi de apenas $12 \%$ e correspondendo somente a sintomas moderados, já que nenhum participante do grupo controle apresentou presença de sintomas depressivos graves (Haase et al., 2004).

\section{Procedimento de Análise dos Dados}

Os cálculos do presente estudo foram realizados com auxílio do software estatístico SPSS (Statistical Package for Social Sciences), versão 12.0. A maioria dos subtestes não apresentou distribuição normal de acordo com os testes Kolmogorov-Smirnoff e Shapiro-Wilks, dessa forma, foram realizadas análises estatísticas não-paramétricas. Foram utilizados os testes $U$ de Mann-Whitney para amostras independentes no intuito de realizar as comparações par a par e análise de Kruskal-Wallis para comparação dos quatro grupos. O critério para significância estatística adotado para as análises de comparação entre os quatro grupos foi o valor de $p<0,05$. Entretanto, para as análises de comparação par a par foi utilizado o critério mais rígido de ajuste de Bonferroni, considerando para a significância estatística valores de $p$ inferiores a 0,001 .

Com o objetivo de verificar a validade de critério da BAMT-UFMG para discriminar o desempenho na MT entre os diferentes grupos, foram realizadas as análises da área sob a curva ROC, considerando o intervalo de confiança de $95 \%$. A validade de critério é estabelecida a partir do cálculo das características de desempenho após haver sido selecionado o ponto de corte que melhor discrimina as duas amostras. Um gráfico ROC é construído representando-se os valores da sensibilidade para os diversos pontos de corte na ordenada e as taxas de falsos positivos ( 1 - especificidade) na abscissa. A área sob a curva ROC (ASC) corresponde ao valor da probabilidade com que o teste discrimina corretamente entre as amostras de indivíduos com a lesão/doença e de indivíduos sem a lesão/doença. Swets (1988) propôs uma categorização dos valores para a área sob a curva como sendo não informativos $(\mathrm{ASC}=0,5)$, de acurácia baixa (valores de ASC entre 0,5 e 0,7), de acurácia moderada (valores de ASC entre 0,7 e 0,9 ) e de alta acurácia (valores de ASC superiores a 0,9 ). O ponto de corte ótimo situa-se o mais próximo possível do canto superior esquerdo do gráfico, ou seja, com elevada sensibilidade e baixa taxa de falso-positivos. 
Análises de regressão múltipla foram calculadas com o objetivo de identificar as varáveis que influenciaram no desempenho das tarefas de MT. O modelo de regressão linear múltipla é definido por Hair, Anderson, Tatham e Black (2005) como um conjunto de técnicas estatísticas que possibilita a análise do relacionamento linear de uma variável dependente com diversas variáveis independentes. Ao se regredir a variável explicada sobre as variáveis explicativas, o resultado final do modelo é uma equação da reta que representa a melhor predição de uma variável dependente a partir de diversas variáveis independentes. Esta equação representa um modelo aditivo, no qual as variáveis preditoras somam-se na explicação da variável explicada. A qualidade do ajuste do modelo de regressão estimado pode ser avaliada por meio do valor do coeficiente de determinação, $R^{2}$. Esse coeficiente calculado indica a percentagem da variação amostral em y que é explicada conjuntamente pelas variáveis independentes presentes no modelo.

\section{Resultados}

Os participantes do grupo de esclerose múltipla apresentaram média de escore no IA igual a 2,22 $(D P=2,50)$ e escore médio no EDSS de 3,16 $(D P=2,22)$, o que indica que apresentavam um comprometimento físico leve, sendo capazes de andar sem auxílio de equipamentos, mas com alguma incapacidade moderada em um dos sistemas funcionais avaliados.

Em relação aos sintomas depressivos, o grupo de controles jovens apresentou média de escore total no Inventário Beck de Depressão de 7,48 pontos $(D P=6,48)$, o grupo de esclerose múltipla não-deprimidos apresentou média de escore no IBD de 6,58 $(D P=4,37)$, o grupo de participantes com esclerose múltipla deprimidos apresentou média no IBD de 23,97 $(D P=7,49)$, enquanto o grupo de idosos apresentou o menor valor médio no IBD correspondente a 2,53 $(D P=3,58)$.

De modo geral, os pacientes com esclerose múltipla deprimidos apresentaram um desempenho inferior nas tarefas da BAMT-UFMG em comparação com os pacientes com esclerose múltipla não-deprimidos. Já o grupo de idosos apresentou o pior desempenho entre os grupos na maioria das tarefas da BAMT-UFMG. Foram calculadas análises de Kruskal-Wallis para comparar o desempenho dos grupos na BAMT-UFMG e os resultados podem ser observados na Tabela 2. O grau de liberdade entre-grupos para o teste de Kruskal-Wallis, em relação aos itens da BAMT foi igual a 3,0.

Tabela 2

Desempenho dos Grupos nos Subtestes da BAMT (Análise de Kruskal-Wallis)

\begin{tabular}{|c|c|c|c|c|c|c|c|c|c|c|}
\hline & \multicolumn{2}{|c|}{$\begin{array}{l}\text { Controles } \\
\text { Jovens }\end{array}$} & \multicolumn{2}{|c|}{ Idosos } & \multicolumn{2}{|c|}{$\begin{array}{l}\text { Esclerose } \\
\text { Múltipla } \\
\text { (não deprimidos) }\end{array}$} & \multicolumn{2}{|c|}{$\begin{array}{c}\text { Esclerose } \\
\text { Múltipla } \\
\text { (deprimidos) }\end{array}$} & \multirow[t]{2}{*}{$\begin{array}{l}\quad H \text { de } \\
\text { Kruskal } \\
\text { Wallis }\end{array}$} & \multirow[t]{2}{*}{$p<$} \\
\hline & Média & $\mathrm{DP}$ & Média & $\mathrm{DP}$ & Média & DP & Média & DP & & \\
\hline \multicolumn{11}{|l|}{ Coordenação de Operações } \\
\hline (Aritmética) & 2,78 & 1,47 & 1,93 & 1,30 & 2,32 & 0,77 & 2,11 & 1,0 & 31,2 & 0,0001 \\
\hline \multicolumn{11}{|l|}{ Coordenação de Operações } \\
\hline (itens verbais) & 2,62 & 1,18 & 1,86 & 1,10 & 2,11 & 0,90 & 1,91 & 0,81 & 42,6 & 0,0001 \\
\hline Armazenamento de Dígitos & 5,61 & 1,19 & 5,05 & 1,02 & 4,94 & 1,25 & 4,73 & 1,07 & 23,1 & 0,0001 \\
\hline Armazenamento de Palavras & 4,29 & 0,89 & 3,59 & 0,91 & 3,89 & 0,75 & 3,45 & 1,59 & 41,2 & 0,0001 \\
\hline Problemas Aritméticos & 12,54 & 4,5 & 8,19 & 4,03 & 10,77 & 3,32 & 9,28 & 4,94 & 34,7 & 0,0001 \\
\hline Compreensão de Sentenças & 5,74 & 2,36 & 3,18 & 1,82 & 3,41 & 1,29 & 3,39 & 1,94 & 52,6 & 0,0001 \\
\hline Velocidade de Processamento total & 62,42 & 18,3 & 39,16 & 15,0 & 48,36 & 16,57 & 43,11 & 18,9 & 58,5 & 0,0001 \\
\hline
\end{tabular}

A Figura 7 apresenta o desempenho dos quatro grupos na tarefa de velocidade de processamento total, demonstrando que houve uma maior lentidão no processamento de informações pelos participantes do grupo de idosos, seguido pelos pacientes com esclerose múltipla deprimidos, menor lentidão dos pacientes com esclerose múltipla não-deprimidos e o melhor desempenho do grupo de controles jovens. É interessante notar que, no gráfico de caixas, houve grande dispersão do desempenho dos participantes do grupo de esclerose múltipla, característico da heterogeneidade cognitiva de portadores de esclerose múltipla.

Foram realizadas análises par a par (comparação entre dois grupos), utilizando o teste não-paramétrico de Mann- 
Ferreira, F. O., Lima, E. P., Vasconcelos, A. G., Lana-Peixoto, M. A. \& Haase, V. G. (2011). Velocidade de Processamento, Sintomas Depressivos e Memória de Trabalho: Comparação entre Idosos e Portadores de Esclerose Múltipla.

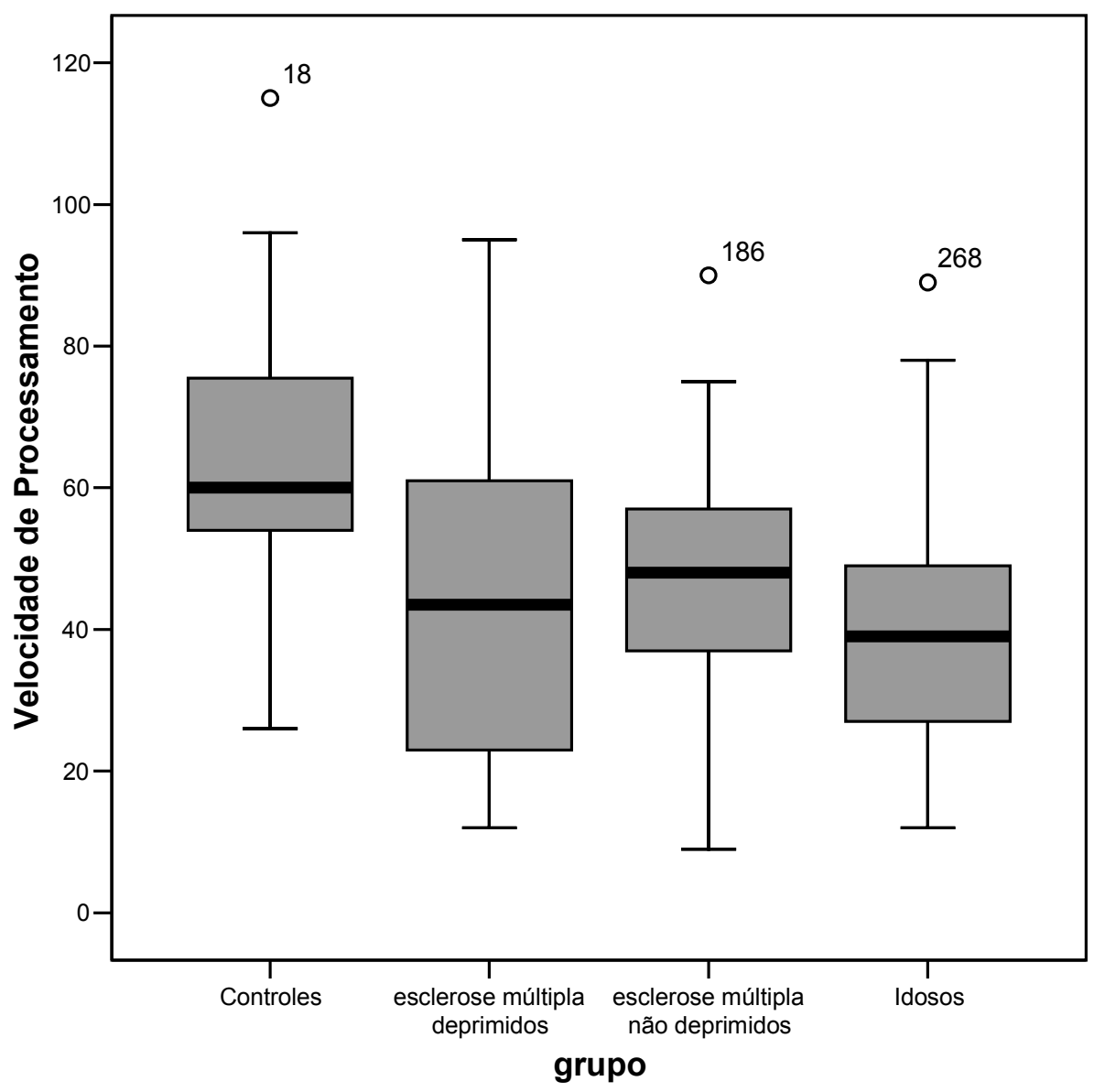

Figura 7. Desempenho dos quatro grupos nos subtestes de velocidade de processamento da BAMT-UFMG

Whitney, para a comparação do desempenho nas tarefas de velocidade de processamento, armazenamento e coordenação de operações. A partir da comparação entre o desempenho dos controles com os pacientes com esclerose múltipla não-deprimidos, verificou-se diferenças estatisticamente significativas, seguindo o critério de ajuste de Bonferroni, apenas na tarefa de velocidade de processamento total $(U=430, p<0,0001)$ e na tarefa de velocidade de compreensão de sentenças $(U=280 ; p$ $<0,0001$ ), habilidade que é prejudicada nessa doença, devido ao processo de desmielinização. Não houve diferenças estatisticamente significativas nas tarefas de armazenamento e coordenação de operações $(p>0,01)$.

Por outro lado, comparando o desempenho de pacientes com esclerose múltipla deprimidos e controles, foram encontradas diferenças significativas nos escores de todos os subtestes (valores de $U$ variando entre 286 e 548; $p<0,0001$ ), com exceção do teste de armazenamento de dígitos $(U=548 ; p>0,001)$ e problemas aritméticos ( $U=492 ; p=0,006)$. O cálculo dos coeficientes $d$ (Cohen, 1992) para a comparação entre controles e pacientes deprimidos com EM revelou que os mesmos foram iguais a 0,53 no teste coordenação aritmética e 0,70 no teste de coordenação verbal.
Na comparação entre o desempenho na BAMT-UFMG de controles jovens e idosos, as diferenças foram significativas para todos os subtestes, o que indicou um desempenho inferior dos idosos, com valores de $U$ variando entre 513 e 2200 , e valor $p<0,0001$. Os coeficientes $d$ calculados para a comparação entre controles jovens e idosos nas tarefas de coordenação originaram coeficientes $d$ iguais a 0,61 e 0,67 , respectivamente, na modalidade numérica e verbal.

Para análise da acurácia da BAMT-UFMG na discriminação entre os grupos, foram realizadas análises da área sob a curva ROC. A análise da curva ROC para comparação entre controles jovens e pacientes com esclerose múltipla deprimidos revelou áreas sob a curva entre 0,62 a 0,75 , (intervalos de confiança entre 0,45 e 0,88 ) o que indica que os subtestes da BAMT-UFMG discriminam apenas com acurácia baixa o desempenho na MT entre controles jovens e pacientes com esclerose múltipla deprimidos. Com relação ao desempenho da BAMT-UFMG para discriminar entre pacientes com esclerose múltipla sem sintomas depressivos e controles, as áreas sob a curva variaram entre 0,48 e 0,57 (intervalos de confiança variando entre 0,35 e 0,80 ), revelando que as tarefas da BAMT-UFMG não discriminam o desempenho cognitivo 
entre pacientes com esclerose múltipla não-deprimidos e controles jovens, uma vez que os pacientes com esclerose múltipla sem sintomas depressivos apresentaram desempenho na BAMT-UFMG semelhante ao desempenho dos controles jovens.

As análises da curva ROC para comparação entre controles jovens e idosos apresentaram áreas sob a curva mais elevadas, variando entre 0,64 e 0,85 (intervalos de confiança variando entre 0,55 e 0,91 ), o que indica uma acurácia em torno de $64 \%$ a $85 \%$ da BAMT-UFMG para discriminar o desempenho cognitivo entre jovens e idosos. A Figura 8 apresenta os gráficos de curva ROC dos subtestes da BAMT-UFMG na comparação entre controles jovens e idosos.

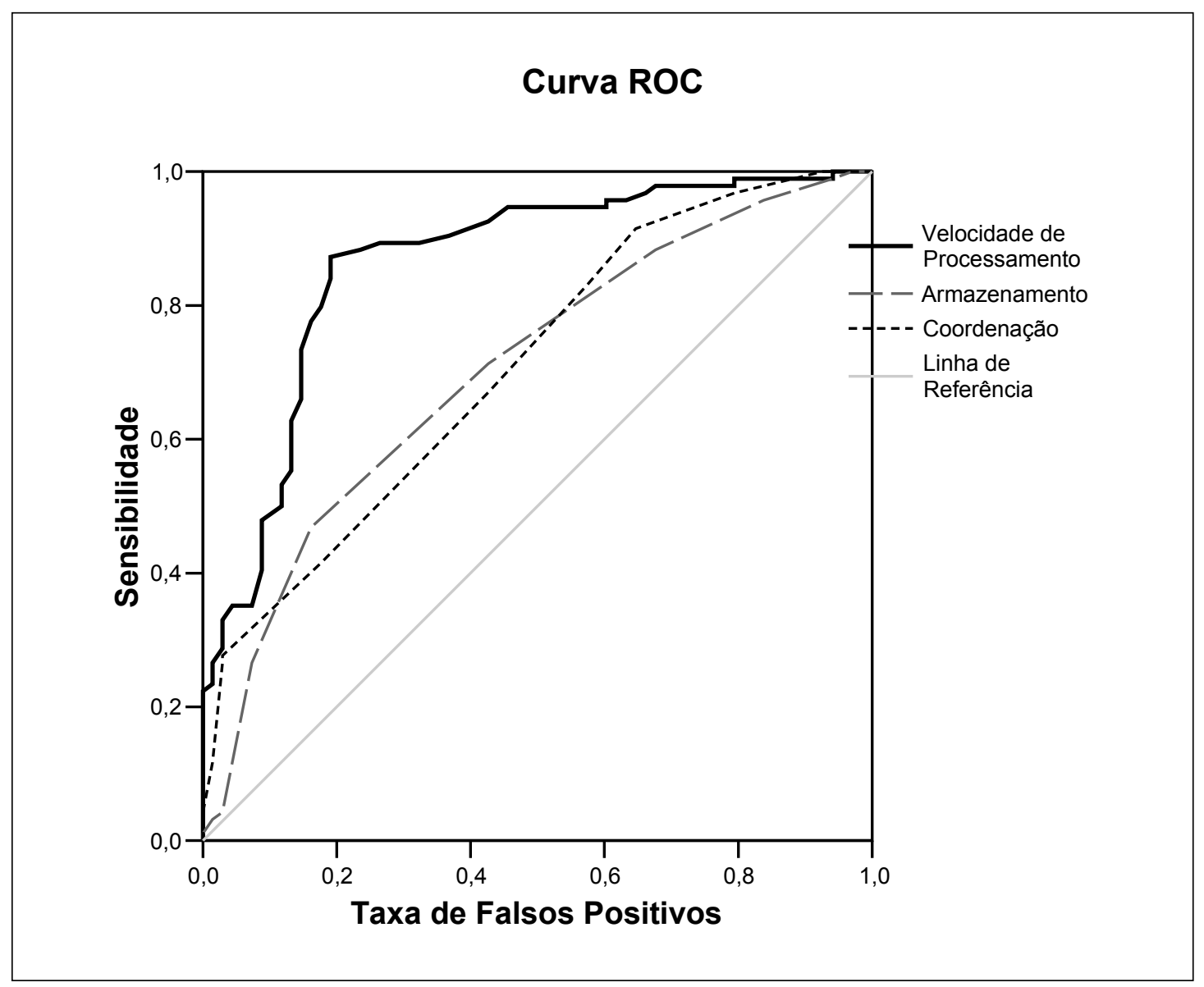

Figura 8. Curvas ROC para os subtestes da BAMT na comparação entre controles jovens e idosos

O modelo de regressão múltipla foi utilizado para avaliar as variáveis capazes de explicar a variação no desempenho dos participantes nas tarefas da BAMT-UFMG. Com o objetivo de verificar a hipótese da influência das variáveis armazenamento e velocidade de processamento no desempenho dos participantes na tarefa de coordenação, em concordância com o modelo de MT de Salthouse e Babcock (1991), foi construído um modelo inserindo a tarefa de coordenação da BAMT-UFMG como variável dependente e as tarefas de armazenamento e velocidade de processamento introduzidas como variáveis independentes. Os escores das tarefas de coordenação e armazenamento foram calculados a partir das médias das modalidades verbal e aritmética, com o objetivo de eliminar possíveis vieses relacionados às habilidades específicas, que são extremamente variáveis entre os partici- pantes. O modelo estimado foi significativo $(p<0,001)$, sendo que as variáveis independentes explicam, conjuntamente, $44,20 \%\left(R^{2}\right.$ adj. $\left.=43,60 \%\right)$ da variação no desempenho na tarefa de coordenação. Dessa forma, foi corroborada a hipótese de que a variação nos escores da tarefa de coordenação pode ser explicada pelas variáveis armazenamento e velocidade de processamento, em concordância com o modelo de Salthouse e Babcock (1991).

Em um segundo momento, com o objetivo de investigar a influência de sintomas depressivos no desempenho em tarefas de MT, o modelo de regressão foi aplicado (método Enter) utilizando como variáveis independentes o escore total no IBD e as variáveis sócio-demográficas dos participantes (escolaridade, sexo, idade). O modelo se mostrou adequado, porém apenas as variáveis idade e o escore total no BDI foram estatisticamente significati- 
Ferreira, F. O., Lima, E. P., Vasconcelos, A. G., Lana-Peixoto, M. A. \& Haase, V. G. (2011). Velocidade de Processamento, Sintomas Depressivos e Memória de Trabalho: Comparação entre Idosos e Portadores de Esclerose Múltipla.

vas $(p<0,05)$ para explicar a variação de $R^{2}=37,20 \%$ $\left(R^{2}\right.$ adj. $\left.=36,40 \%\right)$ no desempenho na tarefa de coordena- ção. Os resultados desse modelo de regressão múltipla podem ser observados na Tabela 3 .

Tabela 3

Modelo de Regressão Múltipla com o Método Enter, para a Variável Dependente Coordenação e Variáveis Independentes Escore Total no IBD e Idade

\begin{tabular}{lccccc}
\hline & $\mathrm{B}$ & $\mathrm{p}<$ & $\mathrm{R}^{2}$ & $\mathrm{R}^{2}$ ajustado & Significância do Modelo \\
\hline Escore total no IBD & $-0,023$ & 0,0001 & 0,372 & 0,364 & $p<0,0001$ \\
Idade & $-0,035$ & 0,0001 & & & \\
\hline
\end{tabular}

Finalmente, a regressão linear múltipla pelo método stepwise foi utilizada para verificar, dentre as variáveis independentes inseridas na equação, aquelas que oferecem uma contribuição significativa ao poder explicativo do modelo. No modelo estimado, foram inseridas como variáveis independentes o escore total no IBD, grupo (controles jovens, idosos, esclerose múltipla deprimidos, esclerose múltipla não-deprimidos), sexo, idade e esco- laridade. Utilizando o método stepwise, as variáveis sexo e grupo foram excluídas no modelo, permanecendo na equação as variáveis escore total no IBD, escolaridade e idade, como variáveis que apresentam uma influência significativa no desempenho na tarefa de coordenação da BAMT-UFMG. O modelo foi significativo apresentando uma variância explicada de $R^{2}=42,1 \%\left(R^{2}\right.$ adj.= $41 \%$ ). Os resultados do modelo de regressão com o método Stepwise podem ser verificados na Tabela 4.

Tabela 4

Modelo de Regressão Múltipla com o Método Stepwise, para a Variável Dependente Coordenação e Variáveis Independentes Escore Total no IBD, Idade, Escolaridade, Sexo e Grupo

\begin{tabular}{lccccc}
\hline & $\mathrm{B}$ & $\mathrm{p}<$ & $\mathrm{R}^{2}$ & $\mathrm{R}^{2}$ ajustado & Significância do Modelo \\
\hline Escore total no IBD & 0,191 & 0,0001 & 42,10 & 41,0 & $p<0,0001$ \\
Idade & $-0,031$ & 0,0001 & & & \\
Escolaridade & 0,06 & 0,0001 & & & \\
\hline
\end{tabular}

\section{Discussão e Considerações Finais}

Com a relação à primeira hipótese, os resultados do estudo mostraram que é possível observar um comprometimento da VPI tanto em portadores de EM quanto em idosos normais, quando comparados a um grupo de adultos mais jovens, com perfil demográfico semelhante ao de portadores de EM. Os resultados indicaram ainda que a lentidão no processamento de informação explicou uma parcela equivalente a cerca de $40 \%$ da variância no desempenho em tarefas de MT. Apesar de ser significativa e substancial, a percentagem de variância explicada foi bem menor do que a aquela relatada por Salthouse (1996; Salthouse \& Babcock, 1991) com relação ao envelhecimento.

Os resultados do presente trabalho replicaram os achados de Arnett et al. (1999), verificando que pacientes portadores de EM deprimidos apresentam um desempenho inferior em tarefas que envolvem o executivo central, em comparação com pacientes portadores de esclerose múltipla não deprimidos e com controles jovens, mas não apresentam prejuízo consistente na habilidade de armazenamento. Entretanto, é importante ressaltar que, apesar de os resultados serem significativos, o valor inferior do intervalo de confiança estimado para a área sob a curva ROC para a comparação entre controles e portadores de EM deprimidos situou-se na faixa de probabilidade definida pelo acaso. Foi detectado um efeito estatisticamente significativo, mas sua magnitude não foi suficiente para discriminar entre os dois grupos com acurácia. Entretanto, a limitação observada na acurácia precisa ser qualificada pelo fato de que os testes de função executiva não são empregados isoladamente nem como marcadores diagnósticos de EM.

Comparativamente ao estudo de Arnett et al. (1999), os resultados aqui apresentados se caracterizaram por serem mais consistentes e por apresentarem uma magnitude de efeito maior. Analisando a Tabela 4 de Arnett et al. $(1999$, p. 554) é possível calcular um coeficiente $d$ igual a 0,40 para a comparação entre controles e pacientes deprimidos com EM na tarefa de alcance de leitura. No presente estudo, as comparações equivalentes originaram coeficientes $d$ entre 0,53 e 0,70 . Adicionalmente, os resultados de Arnett et al. (1999) não foram inteira- 
mente consistentes: os portadores não-deprimidos de EM obtiveram um escore médio mais alto do que os controles no teste de alcance de leitura $(d=0,23)$.

Os sintomas de depressão devem então ser considerados como um agravante potencial dos déficits cognitivos relacionados à EM, contribuindo para a heterogeneidade neuropsicológica observada nesta doença (Lima et al., 2008). Mas a solução para o problema de reduzir a complexidade e variabilidade da expressão sintomática na EM a uma dimensão clinicamente administrável depende da utilização de abordagens estatísticas multivariadas em grandes amostras multicêntricas de pacientes. Usando análise de conglomerados, Lima et al. (2008) demonstraram que pacientes com EM puderam ser distinguidos entre si e de indivíduos normais em função da presença de comprometimentos psiquiátricos ou cognitivos, os quais constituem dimensões parcialmente segregáveis do déficit neurológico associado à doença. Estudos adicionais serão necessários para estabelecer pontos de corte que permitam distinguir com acurácia entre essas diversas dimensões de impacto da EM. A interação entre sintomas depressivos e desempenho cognitivo na EM tem implicações também para o processo de reabilitação. Sabe-se que o humor positivo melhora o desempenho em diversos domínios do funcionamento cognitivo em indivíduos normais (Ashby, Isen, \& Turken, 1999). As bases neurofuncionais das interações entre humor e desempenho cognitivo na EM estão sendo esclarecidas e precisam ser levadas em consideração tanto no diagnóstico quanto na reabilitação neuropsicológicos.

A acurácia da BAMT na comparação entre adultos jovens e idosos foi melhor, situando-se, entretanto, na faixa definida por Swets (1988) como de acurácia baixa (até $70 \%$ ). Mesmo assim, este resultado é importante. Apesar de reduzir a expectativa de vida em cerca de 10 anos (Brønnum-Hansen, Koch-Henriksen, \& Stenager, 2004), a EM não é uma doença fatal e as coortes com EM estão vivendo cada vez mais e atingindo a maior idade (Roberts \& Stuifbergen, 1998). O envelhecimento da população com EM faz com que, aos efeitos da doença se sobreponham as conseqüências da própria senilidade. Normas específicas de desempenho para a população idosa precisam então ser desenvolvidas para o diagnóstico neuropsicológico em indivíduos com EM. Este resultado sugere ainda que os efeitos do envelhecimento cerebral sobre o desempenho em tarefas de MT pode ser mais homogêneo do que as vicissitudes associadas ao curso clínico da EM.

Considera-se que este estudo apresentou diversas limitações. Não foi possível, por exemplo, utilizar exames de ressonância magnética para caracterizar a presença e gravidade das lesões da substância branca em pacientes e idosos. A comparação entre idosos e adultos mais jovens também foi prejudicada pelo fato de que ocorrem diferenças de nível educacional entre os grupos, as quais refletem tendências demográficas mais amplas no perfil educacional da população brasileira. E o nível educacio- nal, conforme comprovado pela análise de regressão é uma das variáveis que interfere no desempenho em testes cognitivos.

Outra limitação importante deve-se a o tamanho amostral insuficiente para se realizar as análises separadamente por forma clínica da esclerose múltipla. Dessa forma, foi necessário realizar as análises estatísticas considerando os pacientes com esclerose múltipla agrupados, seguindo a abordagem mais tradicional de enfatizar as comunalidades clínico-patológicas observadas na esclerose múltipla de forma mais global.

O uso do IBD em indivíduos com EM também pode ser considerado problemático. Alguns itens do questionário interpretam sintomas comuns da $\mathrm{EM}$, tais como fadiga e disfunções vegetativas, como sendo sintomas de depressão, o que seria responsável por uma estimativa exacerbada de depressão na esclerose múltipla, que não corresponderia à realidade (Arnett et al., 1999; Feinstein, 2006). Por outro lado, estudos realizados com amostras de pacientes com EM e com outras patologias revelam que a utilização do IBD com a esclerose múltipla é confiável e acurada (Haase et al., 2004; Lima, 2005; Pujol et al., 1997). Os resultados do presente estudo favorecem a posição de que o IBD é um instrumento válido para aferir os sintomas de depressão na EM. Caso não fosse assim, isto é, se houvesse confusão entre sintomas neurológicos de EM e sintomas depressivos, não teria sido possível detectar os efeitos da depressão sobre o desempenho cognitivo de portadores de EM, inclusive de forma mais consistente e com efeitos maiores do que no estudo de Arnett et al. (1999).

Apesar das limitações inerentes a qualquer estudo empírico, os resultados foram significativos, consistentes entre si e com a literatura revisada, além de apresentarem efeitos de magnitude moderada, indicando que o desempenho em um teste de MT depende da velocidade de processamento, a qual é comprometida em diversas condições tais como a EM e o envelhecimento normal. O desempenho em MT também se revelou sensível aos efeitos da escolarização e à influência de sintomas depressivos em portadores de EM, sugerindo que variáveis neurológicas, sociais e psicológicas interagem de forma complexa na determinação do estado funcional cognitivo e emocional. O efeito destas interações precisa ser levado em consideração no contexto clínico do diagnóstico e reabilitação neuropsicológica. Os resultados estão de acordo com o modelo de limiar para a expressão sintomática neuropsicológica na EM (Calabrese, 2006), e também com o modelo de interação entre múltiplos níveis neuropsicossociais (Feinstein, 2006). O avanço no conhecimento destas interações dependerá da realização de estudos multivariados, com amostras grandes, utilizando instrumentos apropriados e correlacionando os resultados comportamentais com estudos de neuroimagem e resultados de intervenções psicossociais e farmacológicas. Os resultados ilustraram também a importância, ressaltada entre outros por Frisoni e Filippi (2005), de se 
Ferreira, F. O., Lima, E. P., Vasconcelos, A. G., Lana-Peixoto, M. A. \& Haase, V. G. (2011). Velocidade de Processamento, Sintomas Depressivos e Memória de Trabalho: Comparação entre Idosos e Portadores de Esclerose Múltipla.

realizar comparações entre os perfis de comprometimento cognitivo observáveis em diversas condições clínicas e não-clínicas, além da relevância dos conhecimentos neuropatológicos e neurofuncionais na interpretação dos déficits neuropsicológicos. A EM é uma doença que tem tradicionalmente desafiado os modelos localizacionistas clássicos da neuropsicologia (Nocentini et al., 2001). Os resultados do presente estudo mostraram que, em comum com outras doenças que afetam predominantemente a substância branca e com o envelhecimento normal, a VPI pode ser a chave para a correlação estrutura-função.

\section{Referências}

Achiron, A., \& Barak, Y. (2003). Cognitive impairment in probable multiple sclerosis. Journal of Neurology, Neurosurgery \& Psychiatry, 74(4), 443-446.

Alvarenga, P. R. M., \& Quirico-Santos, T. (1997). Fisiopatologia da esclerose múltipla. Aspectos atuais. Revista Brasileira de Neurologia, 33(4), 195-200.

Amato, M. P., Zipoli, V., \& Portaccio, E. (2006). Multiple sclerosis-related cognitive changes: A review of crosssectional and longitudinal studies. Journal of the Neurological Sciences, 245(1-2), 41-46.

Arnett, P. A., Higginson, C., Voss, W., Bender, W. I., Wurst, J. M., \& Tippin, J. M. (1999). Depression in multiple sclerosis: Relationship to working memory capacity. Neuropsychology, 13(4), 546-556.

Arnett, P. A., Rao, S. M., Grafman J., Bernardin, L., Luchetta, T., Binder, J. R., et al. (1997). Executive functions in multiple sclerosis: An analysis of temporal ordering, semantic encoding, and planning abilities. Neuropsychology, 11(4), 535-544.

Ashby, F. G., Isen, A. M., \& Turken, A. U. (1999). A neuropsychological theory of positive affect and its influence on cognition. Psychological Review, 106(3), 529-550.

Baddeley, A. D. (1992). Working memory. Science, 255(5044), 556-559.

Baddeley, A. D. (2003). Working memory: Looking back and looking forward. Nature Reviews Neuroscience, 4(10), 829839.

Benedict, R. H. B., Carone, D. A., \& Bakshi, R. (2004). Correlating brain atrophy with cognitive dysfunction, mood disturbances, and personality disorder in multiple sclerosis. Journal of Neuroimaging, 14(Suppl. 3), 36S-45S.

Brønnum-Hansen, H., Koch-Henriksen, N., \& Stenager, E. (2004). Trends in survival and cause of death in Danish patients with multiple sclerosis. Brain, 127(Pt. 4), 844-850.

Calabrese, P. (2006). Neuropsychology of multiple sclerosis: An overview. Journal of Neurology, 253(Suppl. 1), 10-15.

Campbell, J. J., \& Coffey, C. E. (2001). Neuropsychiatric significance of subcortical hyperintensity. Journal of Neuropsychiatry and Clinical Neurosciences, 13(2), 261-288.

Cohen, J. (1992). Quantitative methods in Psychology: A power prime. Psychological Bulletin, 112(1), 155-159.

Cunha, J. A. (2000). Psicodiagnóstico: Vol. V. Porto Alegre, RS: Artes Médicas.

Cutter, G. R., Baier, M. L., Rudick, R. A., Cookfair, D. L., Fischer, J. S., Petkau, J., et al. (1999). Development of a multiple sclerosis functional composite as a clinical trial outcome measure. Brain, 122(Pt. 5), 871-882.
DeLuca, J., Genova, H. M., Hillary, F. G., \& Wylie, G. (2008). Neural correlates of cognitive fatigue in multiple sclerosis using functional MRI. Journal of the Neurological Sciences, 270(1-2), 28-39.

Demaree, H. A., DeLuca, J. H., Gaudino, E. A., \& Diamond, B. J. (1999). Speed of information processing as a key deficit in multiple sclerosis: Implications for rehabilitation. Journal of Neurology, Neurosurger and Psychiatry, 67(5), 661-663.

Diamond, B. J., Johnson, S. K., Kaufman, M., \& Graves, L. (2008). Relationships between information processing, depression, fatigue and cognition in multiple sclerosis. Archives of Clinical Neuropsychology, 23(2), 189-199.

Feinstein, A. (2006). Mood disorders in multiple sclerosis and the effects on cognition. Journal of Neurological Sciences, 245(1-2), 63-66.

Filley, C. M. (2005). Neurobehavioral aspects of cerebral white matter disorders. Psychiatric Clinics of North America, 28(3), 685-700.

Foong, J., Rozewicz, L., Quaghebeur, G., Davie, C. A., Kartsounis, L. D., Thompson, A. J., et al. (1997). Executive function in multiple sclerosis: The role of frontal lobe pathology. Brain, 120(Pt. 1), 15-26.

Frisoni, G. B., \& Filippi, M. (2005). Multiple sclerosis and Alzheimer disease through the looking glass of MR imaging. American Journal of Neuroradiology, 26(10), 2488-2491.

Godoy, D. V., \& Godoy, R. F. (2002). Redução nos níveis de ansiedade e depressão de pacientes com doença pulmonar obstrutiva crônica (DPOC) participantes de um programa de reabilitação pulmonar. Jornal Brasileiro de Pneumologia, 28(3), 120-124.

Goldman Consensus Group. (2005). The Goldman Consensus statement on depression in multiple sclerosis. Multiple Sclerosis, 11(3), 328-337.

Gorenstein, C., \& Andrade, L. (1998). Inventário de Depressão de Beck: Propriedades psicométricas da versão em Português. Revista de Psiquiatria Clínica, 25(5), 245-250.

Haase, V. G., Lacerda, S. S., Lima, E. P., Corrêa, T. D., Brito, D. C. S., \& Lana-Peixoto, M. A. (2004). Avaliação do funcionamento psicossocial na esclerose múltipla. Arquivos de Neuropsiquiatria, 62(2-A), 282-291.

Hair, J. F., Anderson, R. E., Tatham, R. L., \& Black, W. C. (2005). Análise multivariada de dados. Porto Alegre, RS: Artmed.

Hart, A. B., Laman, J. D., Bauer, J., Blezer, E., Kooyk, Y. V., \& Hintzen, R. Q. (2004). Modelling of multiple sclerosis: Lesson learned in a non-human primate. Lancet Neurology, 3(10), 588-596.

Hauser, S. L., Dawson, D. M., Lehrich, J. R., Beal, M. F., Kevy, S. V., Propper, R. D., et al. (1983). Intensive immunosuppression in progressive multiple sclerosis: A randomized, threearm study of high-doese intravenous cyclophosphamide, plasma exchange and ACTD. New England Journal of Medicine, 308(4), 173-180.

Kail, R., Wolters, C. A., Yu, S. L., \& Hagen, J. W. (2000). Brief report: Speed of information processing in children with insulin-dependent diabetes mellitus. Journal of Pediatric Psychology, 25(7), 515-520.

Kurtzke, J. F. (1983). Rating neurologic impairment in multiple sclerosis: An expanded disability status scale (EDSS). Neurology, 33(11), 1444-1452.

Lana-Peixoto, M. A., Callegaro, D., Moreira, M. A., Campos, G. B., Marchiori, P. E., Gabbai, A. A., et al. (2002). Consenso expandido do BCTRIMS para o tratamento da esclerose múltipla. III. Diretrizes baseadas em evidências e recomendações. Arquivos de Neuropsiquiatria, 50(3-B), 881-886. 
Landro, N., Celius, E. G., \& Stetvold, H. (2004). Depressive symptoms account for deficient information processing speed but not for impaired working memory in early phase multiple sclerosis (MS). Journal of Neurological Sciences, 217(2), 211-216.

Lima, E. P. (2005). Heterogeneidade do perfil neuropsicológico na esclerose múltipla. Dissertação de Mestrado nãopublicada, Universidade Federal de Minas Gerais, Belo Horizonte, $\mathrm{MG}$.

Lima, E. P., Haase, V. G., \& Lana-Peixoto, M. A. (2008). Heterogeneidade neuropsicológica na esclerose múltipla. Psicologia: Reflexão e Crítica, 21(1), 100-109.

Mendes, M. F., Barão Cruz, A., Tilbery, C. P., Balsimelli, S., \& Moreira, M. A. (2003) Depressão na esclerose múltipla forma remitente-recorrente. Arquivos de Neuropsiquiatria, 61(3A), 591-595.

Nocentini, U., Rossini, P. M., Carlesimo, G. A., Graceffa, A., Grasso, M. G., Lupoi, D., et al. (2001). Patterns of cognitive impairment in secondary progressive stable phase of multiple sclerosis: Correlations with MRI findings. European Neurology, 45(1), 11-18.

Pelosi, L., Geesken, J. M., Holly, M., Hayward, M., \& Blumhardt, L. D. (1997). Working memory impairment in early multiple sclerosis. Evidence from an event-related potential study of patients with clinically isolated myelopathy. Brain, 120(11), 2039-2058.

Pujol, J., Bello, J., Deus, J., Martí-Vilalta, J. L., \& Capdevila, A. (1997). Lesions in the left arcuate fasciculus region and depressive symptoms in multiple sclerosis. Neurology, 49(4), 1105-1110.

Rao, S. M. (1986). Neuropsychology of multiple sclerosis: A critical review. Journal of Clinical Experimental Neuropsychology, 8(5), 503-542.

Rao, S. M. (1996). White matter disease and dementia. Brain and Cognition, 31(2), 250-268.

Rao, S. M., Glatt, S., Hammeke, T. A., McQuillen, M. P., Khatri, B. O., Rhodes, A. M., et al. (1985). Chronic progressive multiple sclerosis. Relationship between cerebral ventricular size and neuropsychological impairment. Archives of Neurology, 42(7), 678-682.

Reger, M., Welsh, R., Razani, J., Martin, D. J., \& Boone, K. B. (2002). A meta-analysis of the neuropsychological sequelae of HIV infection. Journal of the International Neuropsyhological Society, 8(3), 410-424.

Roberts, G., \& Stuifbergen, A. K. (1998). Health appraisal models in multiple sclerosis. Social Sciences Medicine, 47(2), 243-253.

Rowland, L. P. (2002). Merrit: Tratado de Neurologia (10. ed.). São Paulo, SP: Guanabara Koogan.

Salthouse, T. A. (1996). The processing-speed theory of adult age differences in cognition. Psychological Bulletin, 103(3), 403-428.

Salthouse, T. A., \& Babcock, R. L. (1991). Decomposing adult age differences in working memory. Developmental Psychology, 27(5), 763-776.

Sayao, A. L., Devonshire, V., \& Tremlett, H. (2007). Longitudinal follow-up of "benign" multiple sclerosis at 20 years. Neurology, 68(7), 496-500.

Stadelmann, C., \& Brück, W. (2008). Interplay between mechanisms of damage and repair in multiple sclerosis. Journal of Neurology, 255(1), 12-18.

Swets, J. A. (1988). Measuring the accuracy of diagnostic systems. Science, 240(4857), 1285-1293.
Tanajura, D., Santos-Jesus, R., Tavares-Neto, J., \& Oliveira I. R. (2002). Prevalence of depression in different groups of inpatients at the University of Bahia, Brazil. Revista Brasileira de Psiquiatria, 24(4), 182-185.

Thornton, A. E., \& Raz, N. (1997). Memory impairment in multiple sclerosis: A quantitative review. Neuropsychology, 11(3), 357-366.

Vodjani, A., Vodjani, E., \& Cooper, E. (2003). Antibodies to myelin basic protein, myelin oligodendrocyties peptides, lymphocyte activation and cytokine production in patients with multiple sclerosis. Journal of Internal Medicine, 254(4), 363-374.

Wood, G. M. O., Carvalho, M. R. S., Rothe-Neves, R., \& Haase, V. G. (2001). Validação da Bateria de Avaliação da Memória de Trabalho (BAMT-UFMG). Psicologia: Reflexão e Crítica, 14(2), 763-776.

Zorzon, M., de Masi, R., Nasuelli, D., Ukmar, M., Mucelli, R. P., Cazzato, G., et al. (2001). Depression and anxiety in multiple sclerosis: A clinical and MRI study in 95 subjects. Journal of Neurology, 248(5), 416-421.
Recebido: 07/08/2008 $1^{a}$ revisão: 08/12/2008 $2^{a}$ revisão: $14 / 12 / 2009$ Aceite final: 12/03/2010 